JSPM 06.03 .20

Commentary $20 / 0480$

Linked Article: Blauvelt et al. Br J Dermatol 2020;

\title{
Choosing a biologic for psoriasis: is it a sprint or a marathon?
}

For patients with psoriasis, both rapid and enduring clearance are highly valued when making treatment choices. ${ }^{1-4}$ Rapidity of clearance has been the focus of two recent network meta-analyses (NMAs) and a systematic review, which conclude that ixekizumab and brodalumab, two agents that inhibit interleukin (IL)-17A, are the fastest-acting treatments when compared with other biologics and conventional systemic agents. ${ }^{5-7}$ Similarly, a study examining the time-effectiveness of simulated induction sequences revealed that initiating treatment with ixekizumab resulted in the shortest time to achieving a clinically significant reduction in dermatology life quality index (DLQI) for $25 \%$ of patients (1.4 weeks). ${ }^{8}$ However, to place these findings in context, a recent update of a Cochrane NMA of overall clinical effectiveness, rather than speed of action, in achieving $\geq 90 \%$ reduction in their Psoriasis Area and Severity Index score (PASI 90) in the induction phase (8-24 weeks), established that infliximab, all the IL-17 inhibitors (ixekizumab, secukinumab, bimekixumab and brodalumab), and IL-23 inhibitors (risankizumab and guselkumab, but not tildrakizumab) were similar in efficacy. ${ }^{9}$

In this issue of the $B J D$, Blauvelt et al. report on the 12-week results of a novel headto-head 24-week trial comparing ixekizumab with guselkumab (IXORA-R). ${ }^{10}$ This is only the second randomized controlled trial to compare an IL-17A inhibitor with an IL-23p19 inhibitor, and is the first to use PASI 100 at 12 weeks as a primary outcome measure. Secondary endpoints focused on speed of response. The final 24-week results for secondary outcomes, including adverse events, have not yet been reported. At 12 weeks there was a significantly higher PASI 100 response for ixekizumab than for guselkumab [215 of 520 patients (41\%) vs. 126 of 507 patients $(25 \%)$, odds ratio 2.14 (95\% confidence interval 1.63-2.81, $P<0.001)$ ], with a response difference of $16.5 \%(10.8-22.2)$. For the secondary endpoints, significantly more patients in the This is the author manuscript accepted for publication and has undergone full peer review but has not been through the copyediting, typesetting, pagination and proofreading process, which may lead to differences between this version and the Version of Record. Please cite this article as doi: 10.1111/BJD.19038

This article is protected by copyright. All rights reserved 
ixekizumab group attained PASI 50 at week 1, PASI 75 at week 2, PASI 90 at weeks 4 and 8 , and PASI 100 at weeks 4 and 8. Patient-reported outcomes were also significantly different; however, the confidence intervals were very close by week 12 , particularly for patient's global assessment of disease severity and DLQI. Of note, there was no significant difference between the two agents in median improvement in PASI at any timepoint. Exploratory analyses suggest that improvement in DLQI was related to early clearance of psoriasis, which was achieved by more patients in the ixekizumab group. Adverse events were similar for both agents, although injectionsite reactions were more common in the ixekizumab group (13\% vs. $3 \%)$. The results support mounting evidence of earlier onset of action for IL-17 inhibitors compared with IL-23 inhibitors; however, it remains uncertain which class of biologic offers superior longer-term efficacy. An earlier head-to-head trial comparing the IL23 and IL-17 inhibitors guselkumab and secukinumab revealed that although secukinumab performed better until week 12 (76\% of patients achieving PASI 90 for secukinumab vs. $69 \%$ for guselkumab), the response declined after week 20 . In contrast, the proportion of patients achieving PASI 90 in the guselkumab group peaked at week 28, surpassing secukinumab, and remained stable until week 48 . The final results at week 48 for PASI 90 were $84 \%$ for guselkumab and $70 \%$ for secukinumab. ${ }^{11}$

The differences in speed of action may in part be due to dosing frequency. Ixekizumab is administered every 2 weeks for the first 12 weeks, whereas guselkumab, after doses at 0 and 4 weeks, is administered every 8 weeks. In addition, the anti-IL-17 agents directly block the effector cytokine, resulting in a more immediate response, whereas the IL-23 inhibitors act proximal to this in the inflammatory cascade, decreasing IL-17 production, possibly explaining the lag in efficacy. However, it is speculated that the broader immunosuppressant effect of the anti-IL-23 agents contributes to a more enduring response. Furthermore, owing to the IL-23 dependence of tissue-resident memory T cells, IL-23 inhibition may be responsible for preventing relapse. ${ }^{11}$

There is no doubt that early and complete clearance is of critical importance to patients; however, evidence of durable response is also essential to making treatment decisions. The 24-week results will be of great interest, as will emergent real-world data from biologics registries. 
Acknowledgments: Thanks to Associate Professor Peter Foley for critically reviewing this commentary.

E. Veysey

${ }^{1}$ Dermatology, St Vincent's Hospital, Melbourne Pty Ltd, Fitzroy, Vic, Australia E-mail: ecveysey@gmail.com

https://orcid.org/0000-0002-1782-9945 (E.V.)

Conflicts of interest: The author(s) declare they have no conflicts of interest.

\section{References}

1 Blome C, Gosau R, Radtke MA et al. Patient-relevant treatment goals in psoriasis. Arch Dermatol Res 2016; 308:69-78.

2 Seston EM, Ashcroft DM, Griffiths CE. Balancing the benefits and risks of drug treatment: a stated-preference, discrete choice experiment with patients with psoriasis. Arch Dermatol 2007; 143:1175-9.

3 Torbica A, Fattore G, Ayala F. Eliciting preferences to inform patient-centred policies: the case of psoriasis. Pharmacoeconomics 2014; 32:209-23.

4 Carrascosa JM, de la Cueva P, Herranz P et al. Perception of psoriasis treatment in the outpatient setting: survey of patients and their prescribing physicians. $J$ Dermatolog Treat 2017; 28:188-99.

5 Warren RB, Gooderham M, Burge R et al. Comparison of cumulative clinical benefits of biologics for the treatment of psoriasis over 16 weeks: results from a network meta-analysis. J Am Acad Dermatol 2019; in press.

6 Warren RB, See K, Burge R et al. Rapid response of biologic treatments of moderate-to-severe plaque psoriasis: a comprehensive investigation using Bayesian and frequentist network meta-analyses. Dermatol Ther (Heidelb) 2020; 10:73-86. 7 Egeberg A, Andersen YMF, Halling-Overgaard AS et al. Systematic review on rapidity of onset of action for interleukin-17 and interleukin-23 inhibitors for psoriasis. J Eur Acad Dermatol Venereol 2020; 34:39-46. 
8 Zidane M, Dressler C, Gaskins M, Nast A. Decision-analytic modeling for timeeffectiveness of the sequence of induction treatments for moderate to severe plaque psoriasis. JAMA Dermatol 2019; in press.

9 Sbidian E, Chaimani A, Afach S et al. Systemic pharmacological treatments for chronic plaque psoriasis: a network meta-analysis. Cochrane Database Syst Rev 2020; 1:CD011535.

10 Blauvelt A, Papp K, Gottlieb A et al. A head-to-head comparison of ixekizumab vs. guselkumab in patients with moderate-to-severe plaque psoriasis: 12 -week efficacy, safety and speed of response from a randomized, double-blinded trial. $\mathrm{Br} J$ Dermatol 2019; in press.

11 Reich K, Armstrong AW, Langley RG et al. Guselkumab versus secukinumab for the treatment of moderate-to-severe psoriasis (ECLIPSE): results from a phase 3, randomised controlled trial. Lancet 2019; 394:831-9.

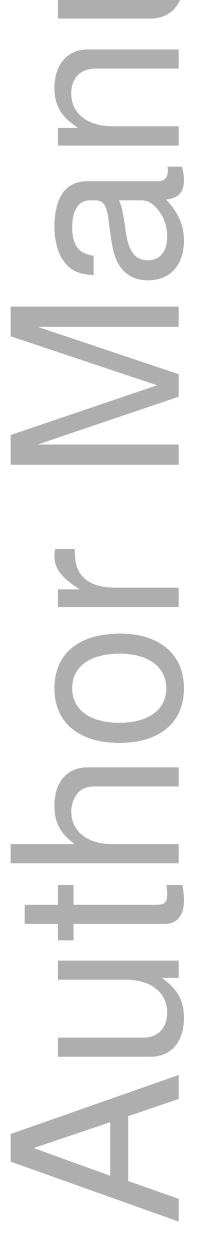




\section{University Library}

\section{- M M I N E R VA A gateway to Melbourne's research publications}

Minerva Access is the Institutional Repository of The University of Melbourne

Author/s:

Veysey, E

Title:

Choosing a biologic for psoriasis: is it a sprint or a marathon?

Date:

2020-04-13

Citation:

Veysey, E. (2020). Choosing a biologic for psoriasis: is it a sprint or a marathon?. BRITISH JOURNAL OF DERMATOLOGY, 182 (6), pp.1321-1322. https://doi.org/10.1111/bjd.19038.

Persistent Link:

http://hdl.handle.net/11343/275624 